\title{
Basic Fibroblast Growth Factor: A Potential Regulator of Proliferation and Intermediate Filament Expression in the Retina
}

\author{
Geoftrey P. Lewis, ${ }^{1}$ Page A. Erickson, ${ }^{1}$ Christopher J. Guérin, ${ }^{1}$ Don H. Anderson, ${ }^{2}$ and Steven K. Fisher ${ }^{1,2}$ \\ ${ }^{1}$ Neuroscience Research Institute and 'Department of Biological Sciences, University of California, Santa Barbara, \\ California 93106
}

\begin{abstract}
Proliferation of astrocytes, and a concomitant increase of intermediate filaments in astrocytes are two fundamental responses of the CNS to injury. We have previously identified these two events in the retina's response to detachment of the neural retina from the adjoining monolayer of retinal pigmented epithelium. In order to analyze the potential role of basic fibroblast growth factor (bFGF) in these responses, we studied cellular proliferation and intermediate filament protein expression in the retinas of cats and rabbits $4 \mathrm{~d}$ and 4 weeks after a single intravitreal injection of $1 \mu \mathrm{g}$ of bFGF. Our results show that bFGF stimulates both of these processes in an otherwise normal eye. The eyes that received bFGF had significantly elevated numbers of ${ }^{3} \mathrm{H}$-thymidinelabeled Müller cells, astrocytes, vascular cells, retinal pigmented epithelial cells, microglia, and macrophages by comparison to control eyes. This proliferation was apparent at $4 \mathrm{~d}$ after the injection of bFGF but not after 4 weeks. In control eyes, antibodies to glial fibrillary acidic protein and vimentin labeled intermediate filaments only in the inner (vitread) portion of the Müller cells, the specialized radial astrocytes that span the width of the retina. In eyes that had been injected with bFGF, almost the entire Müller cell cytoplasm was labeled at $4 \mathrm{~d}$ after injection; after 4 weeks, the cytoplasmic labeling intensity had increased significantly. Release or activation of endogenous stores of bFGF after injury or disease may be involved in the control of cellular proliferation and intermediate filament expression in the retina and elsewhere in the CNS.
\end{abstract}

Injury to the CNS stimulates a complex series of cellular responses in non-neuronal cell types at and close to the site of injury. Cell types that are usually mitotically quiescent including astrocytes, microglia, vascular endothelial cells, as well as invading cells of monocyte/macrophage lineage are stimulated to divide (Bignami, 1986; Seitelberger, 1988; Fisher et al., 1991). In addition, astrocytes enter a phase of hypertrophy accompanied by an increase in the synthesis of vimentin (Calvo et al., 1991) and glial fibrillary acidic protein (GFAP; Mathewson and Berry, 1985; Takamiya et al., 1988) monomers and their assembly into intermediate filaments. These events are of particular interest because they are the defining features of glial "scar

\footnotetext{
Received Feb. 28, 1992; revised Apr. 27, 1992; accepted May 12, 1992.

We thank Dr. Andrew Baird for providing the bFGF, and Kenneth Linberg, Kinga Cetera, and Scott Geller for their technical assistance. The work was supported by U.S. Public Health Service Research Grants EY-00888 (S.K.F) and EY02082 (D.H.A.)

Correspondence should be addressed to Geoffrey $P$. Lewis at the above address

Copyright (C) 1992 Society for Neuroscience $0270-6474 / 92 / 123968-11 \$ 05.00 / 0$
}

formation" in the CNS. The mammalian retina, also part of the CNS and an embryonic outgrowth of the brain, responds similarly to injury. Injuries such as retinal detachment, in which the neural retina is separated from the adjacent monolayer of cuboidal epithelium (the retinal pigmented epithelium, or RPE), appear to induce the full complement of cellular responses characteristic of CNS injury or trauma (Erickson et al., 1983; Hjelmeland and Harvey, 1988; Fisher and Anderson, 1989; Fisher et al., 1991).

When the mammalian retina is experimentally detached, all non-neuronal cell types enter a phase of stimulated DNA synthesis as shown by the incorporation of radiolabeled thymidine into their nuclei. Proliferating cell types include (1) retinal astrocytes that are interspersed among the ganglion cells and their processes, (2) Müller cells - the radial glia that span the sensory retina and that are generally considered to be modified astrocytes (Nork et al., 1987), (3) pericytes and endothelial cells that form the lining of retinal blood vessels, (4) microglial cells, (5) invading monocytes from the circulation, and (6) RPE cells (Anderson et al., 1981, 1983; Erickson et al., 1983; Fisher et al., 1991). The proliferative response in the retina commences within the first day after detachment, reaches a peak about 3-4 d later, and then slowly declines to baseline levels. This time course matches the course of proliferation following brain injury quite closely (Cavanaugh, 1970; Skoff and Vaughn, 1970; Kerns and Hinsman, 1973; Du Bois et al., 1985; Takamiya et al., 1988). In addition to proliferation, Müller's glia show the prototypical intermediate filament response characteristic of astrocytes elsewhere in the CNS (Erickson et al., 1987; Lewis et al., 1989; Guérin et al., 1990a). The cells slowly hypertrophy, filling the retinal space formerly occupied by viable photoreceptor cells and the processes of degenerating neurons, and then migrate along both surfaces of the detached retina (Kroll and Machemer, 1968; VanHorn et al., 1977; Erickson et al., 1983).

A number of cytokines have been proposed as candidate regulatory molecules in the CNS's response to injury (Hjelmeland and Harvey, 1988; Giulian et al., 1989; Bradshaw and Cavanaugh, 1990; Puro et al., 1990; Sporn and Roberts, 1990). In this study, we decided to focus on the potential role of basic fibroblast growth factor (bFGF) in these events for the following reasons: it is relatively abundant in the retina (Glaser et al., 1980; Baird et al., 1985); it has been localized in the retina to various cellular and extracellular locations (Hanneken et al., 1989,1990 ), including the interphotoreceptor matrix that occupies the extracellular space between the neural retina and RPE (Hageman et al., 1991); it is mitogenic for most of the relevant cell types when grown in culture (for reviews, see Gospodarowicz et al., 1986; Baird and Bohlen, 1990); it has been shown 
to upregulate the expression of GFAP in cultured cells (Morrison et al., 1985; Perraud et al., 1988); increased levels of bFGF have bcen obscrved following brain lesions (Finklestein et al., 1988; Gomez-Pinilla et al., 1992); at least some retinal cells are known to express bFGF receptors (Cirillo et al., 1990; Fayein et al., 1990; Noji et al., 1990); and finally, de Juan et al. (1990) have shown using trypsin digests of the retinal vasculature that exogenous bFGF can stimulate the proliferation of feline retinal vascular endothelial cells in vivo.

In this study, we extended those results by injecting bFGF into the vitreous cavity of normal cat and rabbit eyes, and evaluated its effect(s) on both cell proliferation and intermediate filament expression 4 or $28 \mathrm{~d}$ later. The results indicate that exogenous bFGF can induce both responses and therefore reinforce the view that bFGF may play an important regulatory role in the cellular events that accompany injury in the retina and elsewhere in the CNS.

\section{Materials and Methods}

Intraocular injections. Adult cats and rabbits were entrained to a $12 \mathrm{hr} /$ $12 \mathrm{hr}$ light/dark schedule for at least 2 weeks. Animals were anesthetized with $20 \mathrm{mg} / \mathrm{kg}$ Ketaset (ketamine HCl; Parke-Davis, Morris Plains, NJ) and $5 \mathrm{mg} / \mathrm{kg}$ Rompun (xylazine; Miles Labs, Shawne, KS). The eyes then received a single intravitreal injection of either $1 \mu \mathrm{g}$ of human recombinant bFGF (Andrew Baird, Whittier Inst., La Jolla, CA) in 100 $\mu \mathrm{l}$ of a balanced salt solution (BSS; Alcon, Fort Worth, TX) or $100 \mu 1$ of BSS alone, or no injection at all. Ten cat eyes and three rabbit eyes received bFGF; six cat eyes and three rabbit eyes received BSS. Three cat eyes and three rabbit eyes served as normal controls. ${ }^{3} \mathrm{H}$-thymidine $(200 \mu \mathrm{Ci} ; 2.59 \mathrm{TBq} / \mathrm{mmol})$ in $100 \mu \mathrm{l}(70 \mathrm{mCi} / \mathrm{mmol}$ activity; Amersham, Arlington Heights, IL) was injected into the vitreous cavity 24 $\mathrm{hr}$ before death. All the intraocular injections were done through the sclera using a 30 gauge needle, $4 \mathrm{hr}$ into the light period. No signs of intraocular inflammation were observed after any of the injections using indirect ophthalmoscopy.

Tissue preparation. The animals were killed either $4 \mathrm{~d}$ or 4 weeks after the intraocular injection by an overdose of sodium pentobarbital $4 \mathrm{hr}$ after the onset of light. Tissue for autoradiography and immunocytochemistry was cut into quadrants and fixed for $1 \mathrm{hr}$ in $1 \%$ paraformaldehyde and $1 \%$ glutaraldehyde in $0.086 \mathrm{M}$ sodium phosphate buffer (pH 7.2). The tissue was postfixed in $2 \%$ uranyl acetate in maleate buffer for $2 \mathrm{hr}$, dehydrated in increasing concentrations of methanol with $2 \%$ uranyl acetate included in each step, and embedded in LR White resin (Polysciences, Warrington, PA).

${ }^{3} \mathrm{H}$-thymidine autoradiography. Serial $1-\mu \mathrm{m}$-thick sections were cut from similar locations within each retinal quadrant of each eye. Twentyfive consecutive slides were collected, with two sections per slide. All the odd-numbered slides were dipped in a 1:1 mixture of Kodak NTB-2 emulsion (Rochester, NY) and distilled water at $43^{\circ} \mathrm{C}$. The autoradiograms were exposed for $7 \mathrm{~d}$ at $4^{\circ} \mathrm{C}$, developed for $2 \mathrm{~min}$ in full-strength D-19 (Kodak) at $20^{\circ} \mathrm{C}$, washed, fixed, and stained with methylene blueazure II. Thymidine-labeled nuclei were quantified as follows. One section from slides 3,11 , and 21 was selected for counting of labeled nuclei to prevent the possibility of counting the same cell twice. Labeled nuclei were counted and classified by cell type according to their morphology and position in the retina (Fisher et al., 1991). The section length was measured using a calibrated reticule, and the data were tabulated as labeled nuclei/mm retina. The even-numbered, undipped slides were stained and used to help identify the labeled cells.

Immunocytochemistry. Tissue for light microscopic immunocytochemistry was cut from the same blocks as those used for autoradiography. Sections $1 \mu \mathrm{m}$ thick were placed on ProbeOn slides (Fisher Scientific, Pittsburgh, PA) that had been coated with 3-aminopropyltriethoxysilane (Aldrich, Milwaukee, WI) to promote tissue section adhesion to the glass surface. The slides from various conditions were processed together using an automated tissue immunostainer (TechMate 1000 , Biotech Solutions, Inc., Santa Barbara, CA) so that reliable comparisons of labeling intensity could be made.

The sections were first prewetted with phosphate-buffered saline (PBS) containing $0.5 \%$ bovine serum albumin (BSA) and $0.2 \%$ Tween 20 (T20). The sections were blocked with normal goat serum (NGS; 1:100) in PBS/BSA for 30 min, followed by rabbit anti-GFAP (1:200 in PBS/ BSA) and mouse anti-vimentin (1:100 in PBS/BSA; both antibodies from DAKO, Carpenteria, CA) for $2 \mathrm{hr}$. After rinsing with PBS/BSA/ $\mathrm{T}-20$, goat anti-rabbit or goat anti-mouse conjugated to $1 \mathrm{~nm}$ gold spheres (Amersham; both at 1:100 in PBS/BSA) was added for $1 \mathrm{hr}$. The sections were rinsed in PBS/T-20, fixed in $2 \%$ glutaraldehyde in PBS/T-20 for $30 \mathrm{~min}$, and rinsed in distilled water/T-20. At this time, the $1 \mathrm{~nm}$ gold spheres were enlarged using a silver-enhancement technique (Amersham). All sections were enhanced for $25 \mathrm{~min}$ and then rinsed in distilled water/T-20, counterstained in basic fuchsin, rinsed again in distilled water/T-20, and air dried.

Thin sections $(80 \mathrm{~nm})$ for electron microscopic immunocytochemistry were first placed on nickel grids, incubated in NGS for $30 \mathrm{~min}$, blotted, and incubated overnight in anti-vimentin or anti-GFAP (both at 1:400). The next day the grids were rinsed with PBS/BSA and transferred to drops of the secondary antibody for $1 \mathrm{hr}$ (goat anti-mouse or goat antirabbit, $15 \mathrm{~nm} ; 1: 50$ ). After rinsing with PBS/BSA and distilled water, the grids were stained with uranyl acetate for $15 \mathrm{~min}$ and lead citrate for $7 \mathrm{~min}$, exposed to osmium tetroxide vapors for $1 \mathrm{hr}$ ( $2 \%$ osmium tetroxide in PBS), and carhon coated.

\section{Results}

Identification of proliferating cell types

All of the non-neuronal cell types in the retinas of both species, with the exception of the RPE layer in the cat, showed evidence of ${ }^{3} \mathrm{H}$-thymidine incorporation $4 \mathrm{~d}$ after a single injection of bFGF. The labeled cell types were identified by light microscopy as astrocytes, Müller cells, RPE cells, vascular cells (capillary endothelial cells and pericytes), macrophages, or microglia. No neuronal cells were labeled.

Radiolabeled cell nuclei were placed into one of the above six categories on the basis of the cells' morphology and location within the retina. Labeled nuclei within the optic nerve fiber layer of the retina, and those interspersed among axons in the ganglion cell layer, were identified as retinal astrocytes (Fig. $1 \mathrm{~A}-$ $C)$. Labcled nuclei at the margins of the lumens of blood vessels within the inner retina were put into a single vascular cell category irrespective of whether they were endothelial cells or pericytes (Fig. 1A). Labeled nuclei within the outer plexiform layer were categorized as microglia based on their nuclear size and morphology: they have an oval nuclei about $5.5 \mu \mathrm{m}$ long with prominent clumps of heterochromatin, and they were always elongated in the plane of the outer plexiform layer (Fig. 1B). These cells, often referred to as resident macrophages of the CNS, were combined with the labeled cells of the monocyte/ macrophage lineage for the purposes of quantitation. Müller cells were identified by their large, pear-shaped nuclei that are located normally in the proximal portion of the inner nuclear layer (Fig. 1C); however, their nuclei often translocate distally after retinal injuries such as detachment. This was also the case after the bFGF injection (Fig. 1B).

In contrast to the $4 \mathrm{~d}$ time point, no radiolabeled nuclei wcre evident in the autoradiograms of retinal sections from the animals killed 4 weeks after injection of bFGF. Furthermore, the influx of white and, rarely, red blood cells into the retina that was apparent $4 \mathrm{~d}$ after bFGF injection was absent at the 4 week time point. This influx of cells was presumably due to the bFGF since it did not occur after BSS injection. One bFGF-injected eye did develop a multilayered strand of cells that was adherent to the vitreal surface of the retina; there was evidence of cell proliferation within this strand (Fig. 1D).

Retinal sections were also examined in an en face orientation between the inner limiting membrane and the RPE cell layer (Fig. 2A-C). These autoradiograms serve to illustrate the magnitude of the proliferative response associated with specific ret- 

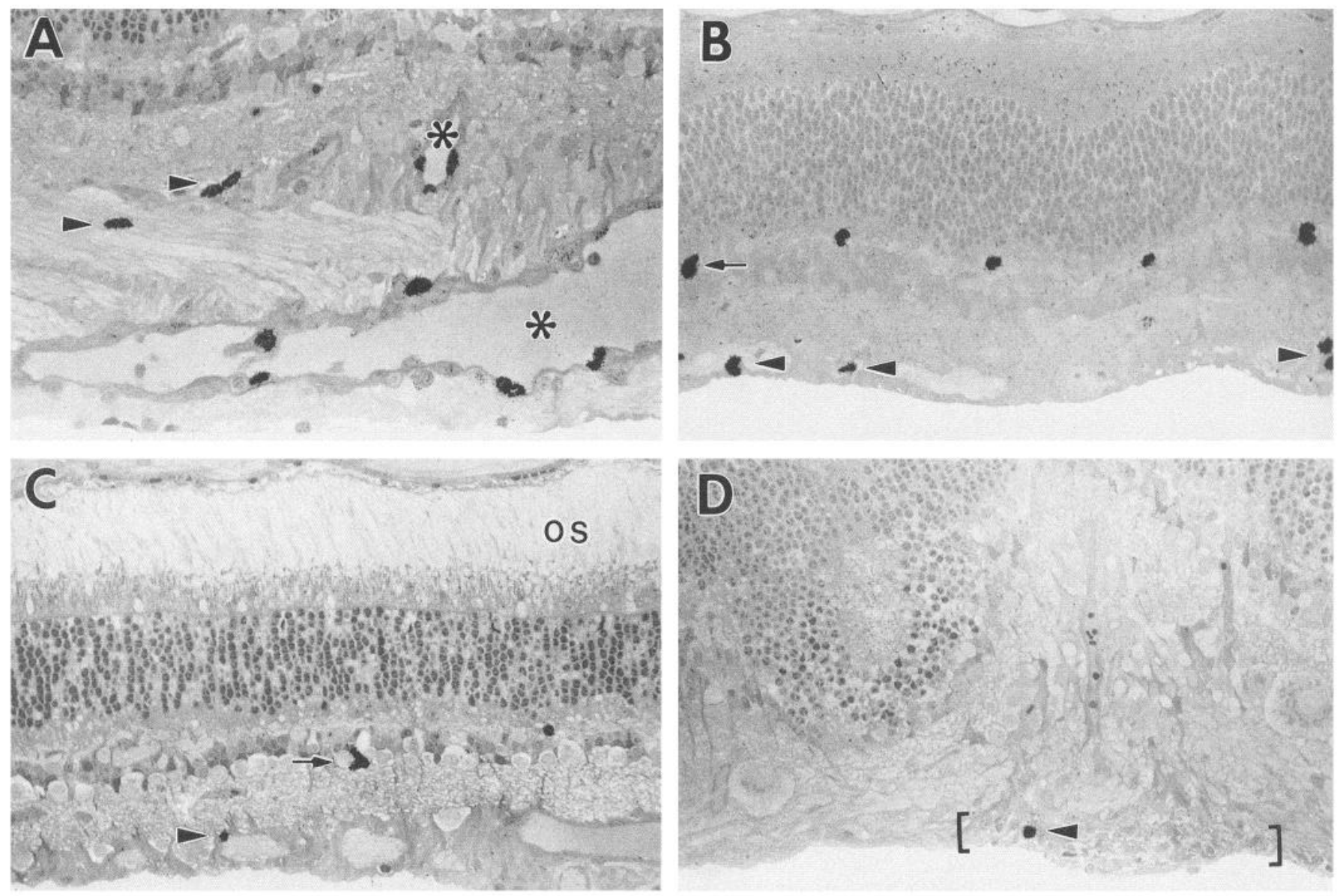

Figure 1. bFGF stimulates a variety of different cell types to incorporate ${ }^{3} \mathrm{H}$-thymidine $4 \mathrm{~d}$ after injection in the cat retina. $A$, Labeled vascular cells associated with the venules and arterioles $\left(^{*}\right)$ and astrocytes (arrowheads) in the nerve fiber layer. B, Astrocytes (arrowheads), microglia (unmarked labeled cells), and a displaced Müller cell nuclei (arrow). C, A Müller cell in its normal location (arrow), in addition to an astrocyte (arrowhead), and a microglial cell (unmarked labeled cell). No intraretinal cells were labeled 4 weeks after bFGF injection, although the multilayered strand of cells $(D$, brackets $)$ that formed on the retinal surface of one eye did contain a dividing cell $(D$, arrowhead $)$. The disruption of the photoreceptor outer segments $(O S)$ in $C$ is a fixation artifact. Magnification, 262 .

inal layers. Compare, for example, the numbers of labeled astrocytic and vascular cell nuclei in this orientation with the number of labeled cells in Figure 1.

\section{Quantitation of the proliferative response}

The number of radiolabeled nuclei/mm of cat retina was quantified at the $4 \mathrm{~d}$ time point for each cell category. A histogram depicting the results from the cat is shown in Figure 3. In the normal retinas, only a few vascular cell nuclei $(0.04 / \mathrm{mm})$ and microglia/macrophage nuclei $(0.02 / \mathrm{mm})$ were labeled. The BSSinjected eyes showed a slight increase over the baseline levels in the numbers of labeled astrocytes $(0.52 / \mathrm{mm})$ and microglia/ macrophages $(0.28 / \mathrm{mm})$. This demonstrates that the retina is quite sensitive to even the slightest insult such as a needle penetration. In the bFGF-injected eyes, however, there was a dramatic increase in the number of labeled Müller cells $(0.92 / \mathrm{mm})$, astrocytes $(6.76 / \mathrm{mm})$, vascular cells $(1.16 / \mathrm{mm})$, and microglia/ macrophages $(2.14 / \mathrm{mm})$. There was no evidence of RPE cell labeling.

Similar results were obtained in the rabbits (Fig. 4). In normal eyes, we identified a low number of labeled astrocytes $(0.12$ / $\mathrm{mm})$, vascular cells $(0.07 / \mathrm{mm})$, and microglia/macrophages $(0.08 / \mathrm{mm})$. After a BSS injection, a slight elevation of labeled cells in all categories was identified: Müller cells $(0.04 / \mathrm{mm})$, astrocytes $(0.53 / \mathrm{mm})$, vascular cells $(0.04 / \mathrm{mm})$, RPE cells $(0.01 /$ $\mathrm{mm})$ and microglia/macrophages $(0.16 / \mathrm{mm})$. In eyes receiving bFGF, there was a large increase in the number of labeled nuclei in each category: Müller cells $(0.68 / \mathrm{mm})$, astrocytes $(6.99 / \mathrm{mm})$, vascular cells $(18.53 / \mathrm{mm})$, RPE cells $(0.98 / \mathrm{mm})$, and microglia/ macrophages $(0.62 / \mathrm{mm})$. Although these data indicate clearly that all non-neuronal retinal cell types proliferate to some degree in response to exogenous bFGF, it is not possible to make quantitative comparisons between cell types in the magnitude of their individual responses without also knowing the total population of the various cell types. Similarly, the data do not allow us to make accurate quantitative comparisons between species in the magnitude of the response for single cell types.

\section{Intermediate filament response}

Four days after a BSS injection in the cat, anti-vimentin labeling of Müller cell processes extended into the outer plexiform layer (Fig. 5A, OPL) and anti-GFAP labeling extended into the inner nuclear layer (Fig. $6 A$, INL). A large increase in labeling with both antibodies was observec $4 \mathrm{~d}$ after the bFGF injection, with labeling extending from the endfoot region of the Müller cells well into the outer nuclear layer (ONL) and with much more intense labeling of the endfoot region than in BSS controls (Figs. $5 B, 6 B)$. Four weeks after a single injection of BSS, the labeling 

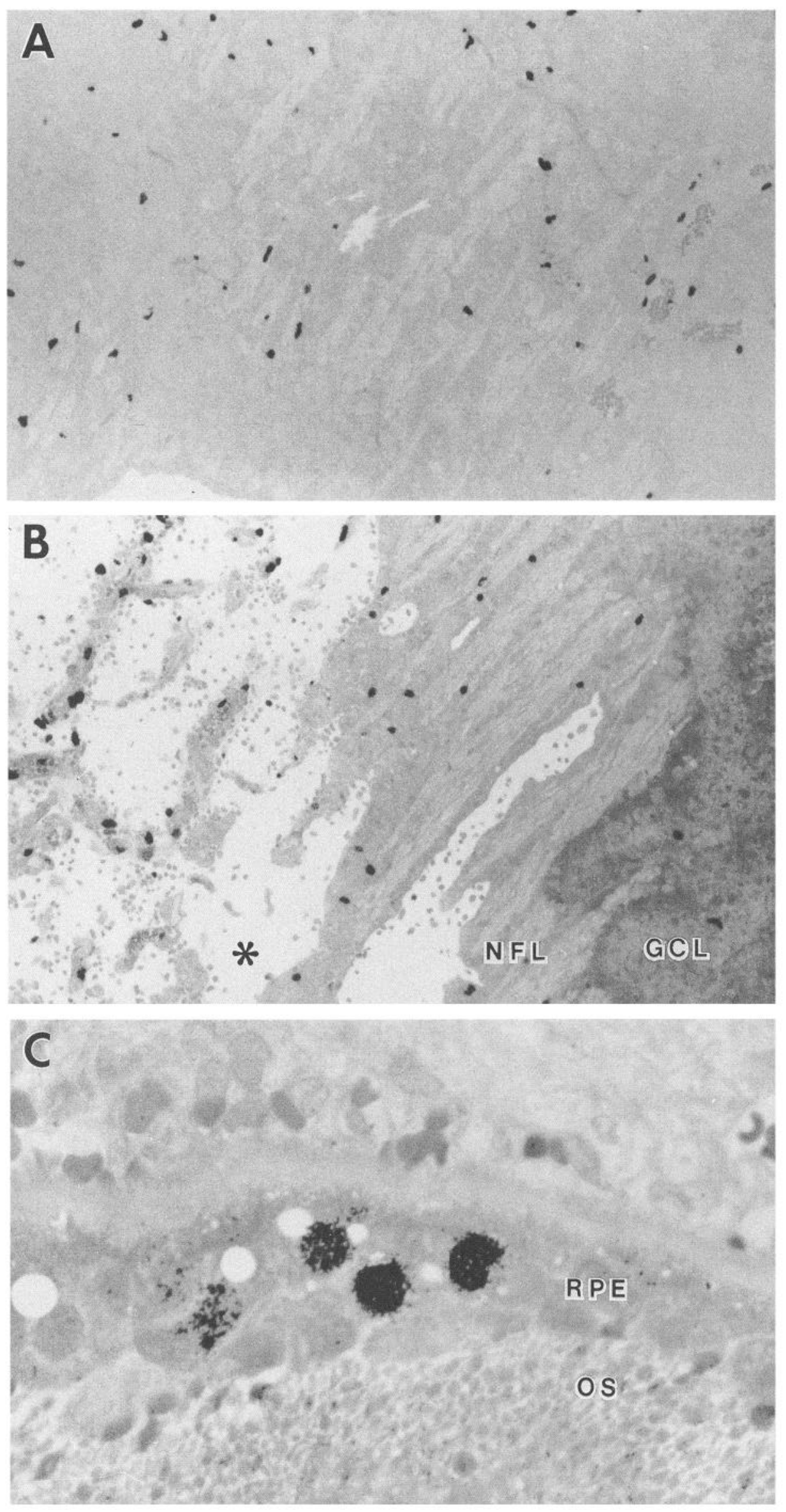

Figure 2. The magnitude of the proliferative response is demonstrated in en face-oriented ${ }^{3} \mathrm{H}$-thymidine autoradiograms $4 \mathrm{~d}$ after bFGF injection. $A$, Astrocytes and vascular cells in the ganglion cell layer of the cat retina. $B, A s-$ trocytes in the nerve fiber layer (NFL) and ganglion cell layer $(G C L)$ in the rabbit retina, in addition to vascular cells present in blood vessels within the vitreous $\left(^{*}\right) . C, R P E$ cells in the rabbit retina. $O S$, photoreceptor outer segments. Magnification: $A$ and $B, 362 \times ; C$, $1920 \times$. 
Figure 3. The numbers of labeled nuclei/mm cat retina for each cell type are shown at the $4 \mathrm{~d}$ time point. In the normal eyes very few cells are labeled. After an injection of BSS, there is a slight increase in labeled astrocytes and cells in the microglia/macrophage category. After an injection of bFGF, there is a dramatic increase in labeled Müller cells, astrocytes, vascular cells, and microglia/macrophages, although no labeled RPE cells were observed. Error bars show SEM.

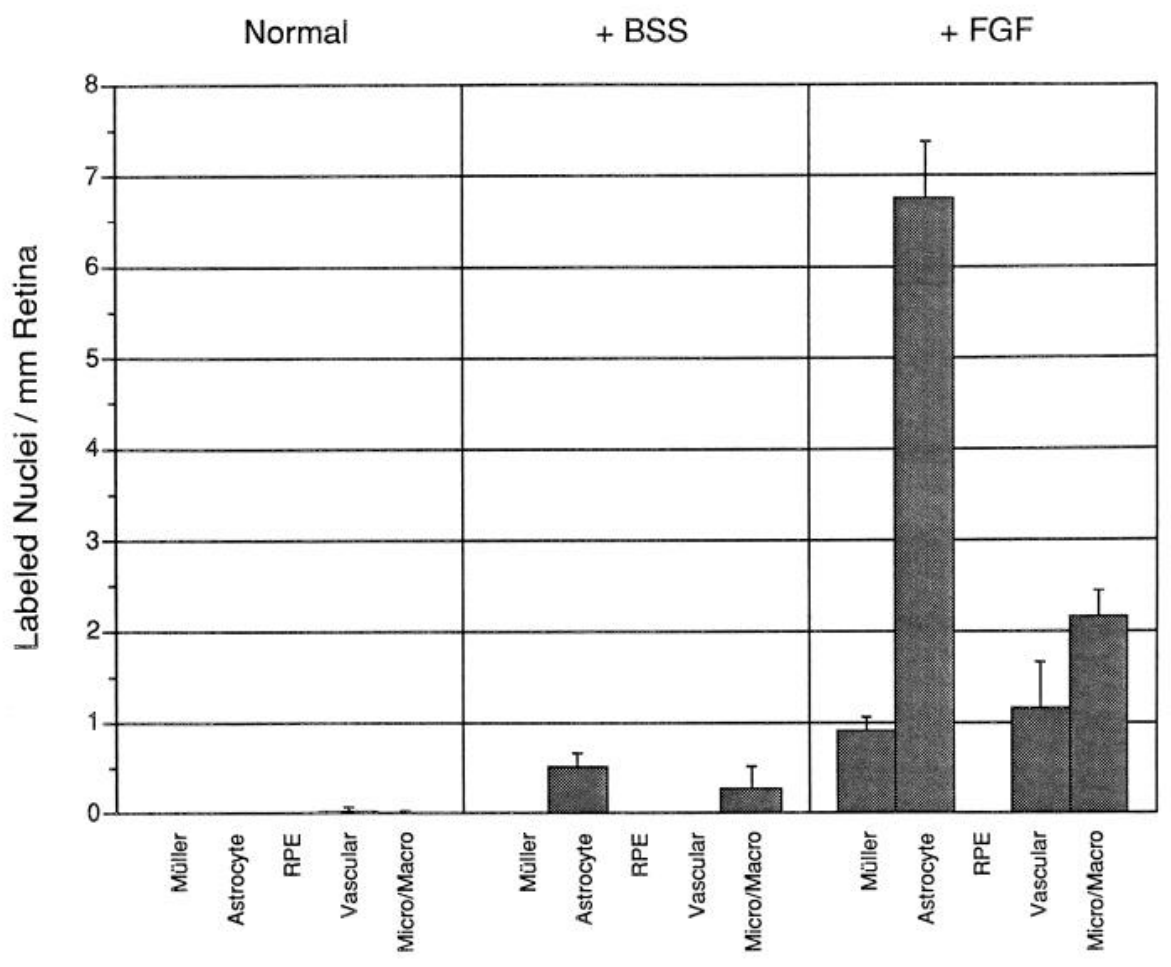

intensity increased slightly over the $4 \mathrm{~d}$ BSS control (Figs. $5 C$, $6 C$ ). Four weeks after the injection of bFGF, however, there was very heavy labeling extending across the retina to the termination of the Müller cells at the outer limiting membrane (Figs. 5D, 6D). In normal eyes that did not receive an injection, anti-vimentin and anti-GFAP labeling within the Müller cell cytoplasm was similar to the BSS controls (Figs. $5 E, 6 E$ ). The multilayered strand of cells that developed in one eye 4 weeks after bFGF injection was labeled with both intermediate fila- ment antibodies (Fig. $5 F, 6 F$ ). Because retinal astrocytes normally have relatively high levels of intermediate filaments throughout their cytoplasm, it was difficult to detect any change in intermediate filament expression in this cell type after bFGF injection.

Because the antibodies label intermediate filament proteins in both the monomeric and filamentous form, we determined by electron microscopic immunocytochemistry that there was indeed a concomitant increase in immunolabeled $10 \mathrm{~nm}$ fila-
Figure 4. The numbers of labeled nuclei $/ \mathrm{mm}$ rabbit retina for each cell type are shown at the $4 \mathrm{~d}$ time point. In the normal eyes, very few cells are labeled. After an injection of BSS, there is a slight increase in the number of labeled Müller cells and astrocytes. After an injection of bFGF, there is a large increase in the number of labeled nuclei in each category. Error bars show SEM.

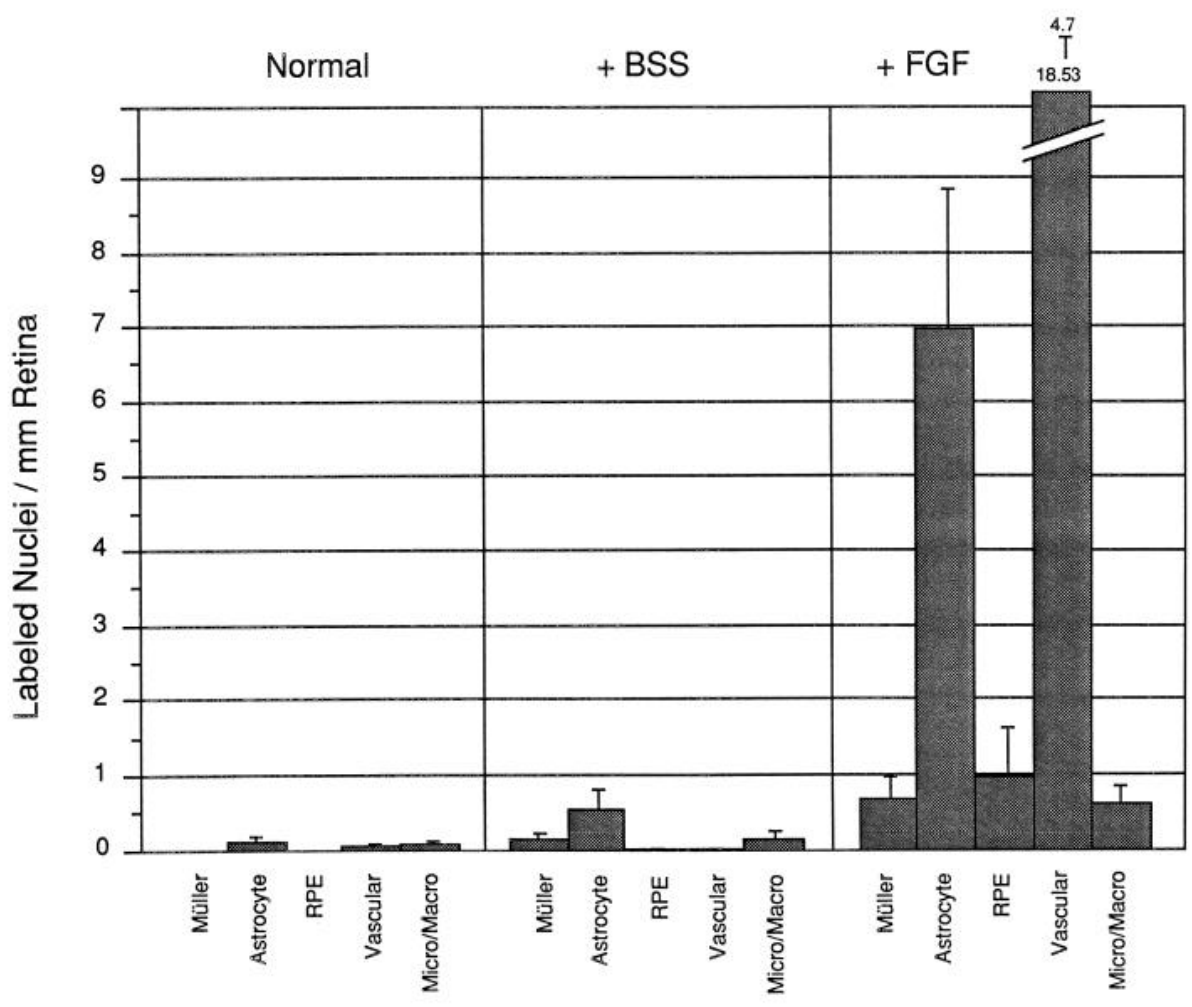



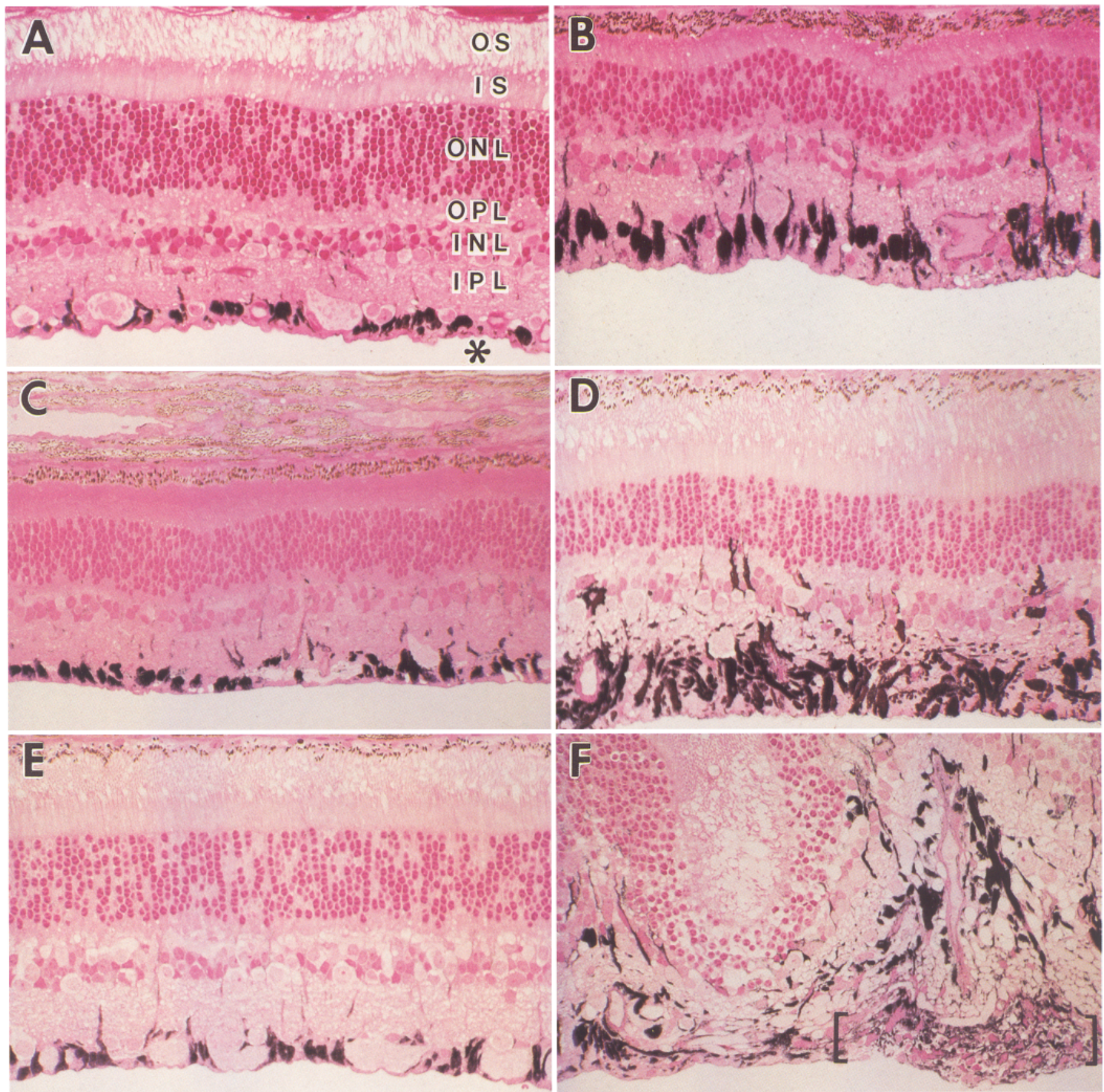

Figure 5. Anti-vimentin immunolabeling increases after bFGF injection in the cat retina. $A$, Four days after an injection of BSS, labeling within the Müller cell cytoplasm extends from the endfoot (the region of the cell that borders the vitreous cavity; $\left.{ }^{*}\right)$ into the outer plexiform layer $(O P L)$. $B$, Four days after a bFGF injection, labeling extends well into the outer nuclear layer (ONL), with more intense labeling of the endfoot region. $C$, Four weeks after a BSS injection, there is only a slight increase in vimentin labeling over the $4 \mathrm{~d}$ time point. $D$, Four weeks after a bFGF injection, labeling extends through the ONL with very heavy labeling of the endfoot region. $E$, In normal eyes that did not receive an injection, anti-vimentin labeling is similar to the BSS controls in $A$ and $C$. F , The multilayered strand of cells that formed on the vitreal surface of the retina after 4 weeks, also labels with anti-vimentin (brackets). $O S$, outer segment; $I S$, inner segment; $I N L$, inner nuclear layer; $I P L$, inner plexiform layer. Magnification, $250 \times$.

ments in the Müller cells. Large masses of anti-vimentin-labeled intermediate filaments were observed in the ONL after the injection of bFGF (Fig. 7A; 4 weeks). Accompanying this labeling was the extensive hypertrophy of Müller cells observed at the 4 week time point. Very few intermediate filaments were found in this region after a BSS injection, and there was no indication of Müller cell hypertrophy (Fig. 7B; 4 weeks).

\section{Discussion}

Understanding the molecular regulation of events that occur after injury to the CNS will greatly facilitate the search for ways to arrest or alleviate the functional deficits that often accompany such injury. Severe visual impairment or blindness is often the consequence of injury to the neural retina. We have reported 

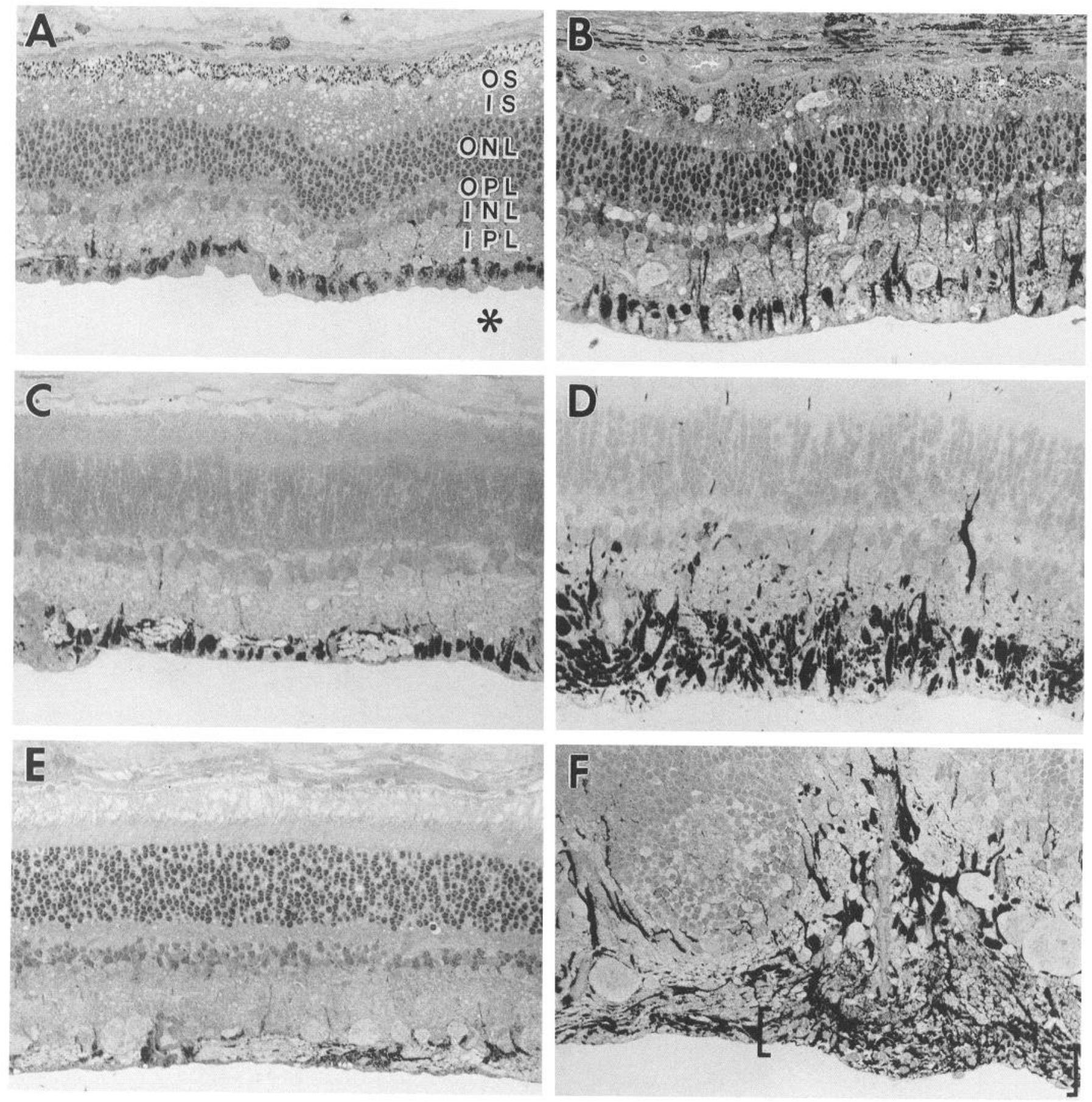

Figure 6. Anti-GFAP immunolabeling increases after bFGF injection in the cat retina. $A$, Four days after an injection of BSS, labeling within the Müller cell cytoplasm extends from the endfoot (the region of the cell that borders the vitreous cavity; ${ }^{*}$ ) into the inner plexiform layer $(I P L)$. $B$, Four days after an injection of bFGF, labeling extends well into the ONL. $C$, Four weeks after an injection of BSS, labeling increases only slightly, now extending into the inner nuclear layer $(I N L)$. D, Four weeks after bFGF injection, there is a large increase in labeling in the endfoot region, with thick processes many times labeling through the ONL. $E$, In normal eyes that did not receive an injection, labeling is similar to the BSS controls in $A$ and $C . F$, The multilayered strand of cells that formed on the vitreal surface of the retina after 4 weeks, also labels with anti-GFAP (brackets). OS, outer segment; $I S$, inner segment; $O P L$, outer plexiform layer. Magnification, $262 \times$.

previously that one experimental model of retinal injury, retinal detachment, induces a phase of stimulated DNA synthesis in all non-neuronal cell types within the detached region (Fisher et al., 1991), including the adjacent RPE cells (Anderson et al., 1981). Similarly, we have reported that detachment stimulates an increase in the expression of GFAP and vimentin-containing intermediate filaments in Müller cells (Erickson et al., 1987;
Lewis et al., 1989; Guérin et al., 1990a). The onset of both responses occurs within the first day following detachment. The proliferative response reaches its maximum approximately 3$4 \mathrm{~d}$ following detachment; the peak in the intermediate filament response remains unknown. Because elevated levels of proliferating cells also occur outside the zone of detached retina, we proposed that one or more diffusible factors (cytokines) may be 

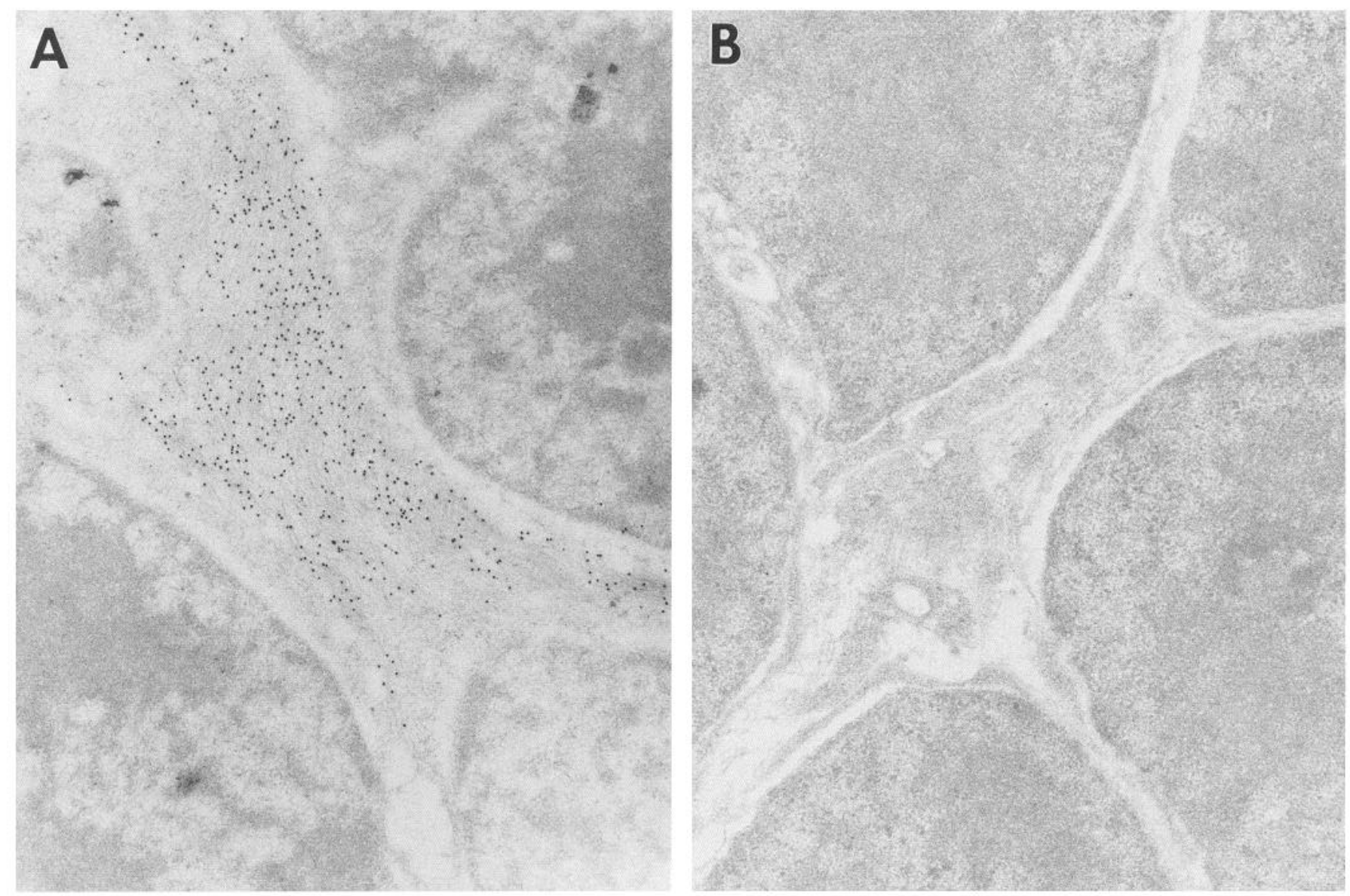

Figure 7. Electron microscopic immunocytochemistry reveals an increase in $10 \mathrm{~nm}$ filaments after bFGF injection. $A$, Four weeks after an injection of bFGF, $10 \mathrm{~nm}$ filaments are observed in Müller cells within the ONL of the cat retina, and these filaments label with anti-vimentin (15 nm gold spheres). $B$, Four weeks after a BSS injection, no labeling with anti-vimentin is observed in a similar retinal region. The nuclei in $A$ and $B$ are photoreceptor nuclei. Magnification, 22,000×.

involved in eliciting the proliferative response (Fisher et al., 1991).

Given the relatively high concentration of bFGF within the neural retina (Glaser et al., 1980; Baird et al., 1985), its known mitogenic properties, and its effect on intermediate filament biosynthesis in cultured cells (Morrison et al., 1985; Perraud et al., 1988), we decided initially to examine the potential role of this factor in these cellular events. As a first step in this process, an immunohistochemical study was undertaken to determine the locations where bFGF is present in the normal primate retina. The results showed bFGF antibody binding to various intracellular and extracellular sites including the inner limiting membrane, the Müller cell cytoplasm, and, most notably, to the extracellular matrix between the neural retina and the RPEthe so-called interphotoreceptor matrix (Hageman et al., 1991). This finding, in conjunction with other related data indicating that interphotoreceptor matrix components can be identified in the vitreous of some human patients with retinal tears (Russell and Hageman, 1991), suggests that endogenous stores of extracellular bFGF sequestered within the interphotoreceptor matrix could be released and/or activated whenever the relationship between the neural retina and RPE is compromised by injury or disease.

In an attempt to mimic the sudden release or activation of endogenous bFGF that could occur under such pathological conditions, we injected bFGF directly into the vitreous cavity of normal eyes and then evaluated the proliferative and intermediate filament responses of the retina $4 \mathrm{~d}$ and $28 \mathrm{~d}$ after injection. The results indicate clearly that exogenous bFGF can mimic the responses to retinal injury in several important respects. Both exogenous bFGF and experimental retinal detachment stimulate ${ }^{3} \mathrm{H}$-thymidine incorporation and induce cellular proliferation in all non-neuronal retinal cell types. The response of the ganglion cell layer astrocytes and Müller cells is particularly significant because it mimics the response of astrocytes to injuries elsewhere in the CNS. Both experimental treatments produced an apparent upregulation in the levels of two intermediate filament proteins, GFAP and vimentin, within Müller's glia. Both treatments led to the hypertrophy of Müller's glia and migration of their nuclei from their normal positions within the retina. Finally, both treatments resulted in an influx of white cells from the circulation that were identified by light microscopy as either monocytes or mature macrophages. Although we have demonstrated that bFGF can mimic the response observed after retinal detachment, this does not rule out the possibility that other growth factors may be involved. To determine more precisely the role of bFGF after injury, we are currently examining whether there is a change in the levels of bFGF or its receptor after retinal detachment.

Our attempt to estimate the magnitude of the proliferative response suggests that it may be quite extensive-close to two million cells would be expected to enter a phase of DNA syn- 
thesis in a piece of retina $1 \mathrm{~cm} \times 1 \mathrm{~cm}$. These calculations were made using several assumptions. Based on other data showing that the half-life of small molecules in the vitreous cavity is 4 hr or less, ${ }^{3} \mathrm{H}$-thymidine is probably available for incorporation into retinal cells for approximately $2-3 \mathrm{hr}$ after intravitreal injection (Peyman and Bok, 1972; Lee et al., 1989). If we assume that most ${ }^{3} \mathrm{H}$-thymidine incorporation into retinal nuclei occurred within the $2 \mathrm{hr}$ time frame, and that the level of incorporation during that interval was representative for day 4 as a whole, then we can estimate the total number of cells expected to enter S-phase on that day. Using those assumptions, we can estimate that roughly $2 \times 10^{6}$ cells in a piece of retina $1 \mathrm{~cm} \times$ $1 \mathrm{~cm}$ enter S-phase on day 4 following bFGF injection. [The number of labeled nuclei/mm retina $(11 / \mathrm{mm})$ for a $2 \mathrm{hr}$ pulse was corrected for overlapping nuclear counts using the method of Abercrombie (1946). The corrected count $(1.54 / \mathrm{mm})$ was multiplied by $10^{2}$ to yield the number of labeled cells on a single $1 \mathrm{~cm}^{2}, 1-\mu \mathrm{m}$-thick section, and then by $10^{3}$ to obtain the number of labeled cells in a piece of retina $1 \mathrm{~cm} \times 1 \mathrm{~cm}$. This number was then multiplied by 12 to obtain the total number of labeled cells expected in one $24 \mathrm{hr}$ period.]

In this study, RPE cell labeling was observed only in the rabbit and not in the cat. It is not clear whether the lack of labeling in the cat means the factor did not reach this cell layer or that there is a species difference in responsiveness of this cell type. In general, the rabbit retina appears more reactive to insult than the cat retina, which in turn may be related to the fact that the rabbit retina is "avascular." That is, its retinal vessels all lie on the vitreal surface of the retina associated with the medullary ray layer, whereas those of the cat (and human) retina lie in beds that extend as deep as the outer plexiform layer.

de Juan et al. (1990) reported that an intravitreal injection of heat-inactivated bFGF did not stimulate proliferation, suggesting that simply the injection of protein into the vitreous cavity does not induce the response. In this study, control eyes that received a BSS injection showed a consistent but slight increase in the number of ${ }^{3} \mathrm{H}$-thymidine-labeled cells, demonstrating that the retina responds to what may regarded as minimal injury produced by an intravitreal injection through a 30 gauge needle.

An upregulation in intermediate filament expression is one of the characteristic responses of glial scar formation after CNS injury (Mathewson and Berry, 1985; Bignami, 1986; Takamiya et al., 1988). Müller cells undergo an analogous response following detachment and in conjunction with other types of retinal injuries or diseases (for reviews, see Hjelmeland and Harvey, 1988; Fisher and Anderson, 1989). In normal Müller cells, intermediate filaments are restricted to the most vitread portion of the cells' cytoplasm (Bignami and Dahl, 1979; O'Dowd and Eng, 1979; Bjorkland et al., 1985; Kivela et al., 1986; Erickson et al., 1987; Lewis et al., 1988, 1989). Both detachment and the exogenous bFGF induce a rapid increase in the levels of both intermediate filament proteins in these cells. By $4 \mathrm{~d}$ postinjection or postdetachment, intermediate filament bundles extend distally well beyond their normal cytoplasmic position in the inner retina. This response continued well beyond $4 \mathrm{~d}$ because there was a dramatic increase in the intensity and extent of immunolabeling for both proteins in the $28 \mathrm{~d}$ animals. It is possible that the increase in intermediate filaments is linked to the proliferation of Müller cells, although this seems unlikely because the number of proliferating Müller cells appears to be much smaller than those showing indications of increased interme- diate filament expression. Other studies of GFAP induction have reached the same conclusion, namely, that intermediate flament upregulation and ccll division are not causally linked (Backhovens et al., 1987; Miyake et al., 1988; Takamiya et al., 1988). Indeed, the precise function of the intermediate filaments and their response during astrocytic gliosis remains unknown. It is highly likely, however, that they are involved in the remodeling of these cells as they undergo hypertrophy.

It is noteworthy that evidence of cell proliferation was found within the outer plexiform layer of the retina. These radiolabeled cells were identified by light microscopy as microglia (Boycott and Hopkins, 1981), the resident macrophage population in the retina. The role of retinal microglia remains obscure, although data from elsewhere in the CNS suggest that their "activation" by injury can lead to the release of regulatory peptides such as interleukin-1 (Giulian and Lachman, 1985). Invading macrophages are also known to introduce several other factors at sites of local CNS injury or trauma (Giulian and Ingeman, 1988; Giulian ct al., 1989). These data, along with the admittedly complex nature of the brain's response to injury, imply that its regulation is not likely to be limited to one factor, but may also involve other regulatory peptides acting in concert or as part of a cascade.

Glial and epithelial cell proliferation within the retina is of clinical significance because displaced cells can migrate along the vitreal surface of the sensory retina or on the surface defined by the distal portion of the photoreceptor cells (i.e., the inner and outer segments). There they proliferate further and form multilayered, cellular assemblages. These pathologies are known as proliferative vitreoretinopathy and subretinal fibrosis, respectively (for reviews, see Hjelmeland and Harvey, 1988; Fisher and Anderson, 1989), and both Müller cells and astrocytes have been identified as components of these cellular strands (Van Horn et al., 1977; Machemer, 1978; Hiskott et al., 1984a,b; Gućrin et al., 1990b). Therapeutically, acquiring the capacity to prevent the adherence and inhibit the subsequent growth of such strands is highly desirable because they can lead to recurrent retinal detachment and blindness in the affected eye.

The results from this study indicate that bFGF may play an important regulatory role in the response of non-neuronal cells to CNS injury. Gliosis (proliferation, hypertrophy, and an upregulation of intermediate filament proteins), microglial activation, the proliferation of cells of the vasculature, and an influx of macrophages are all components of this complex response, and all were induced by the injection of bFGF into the vitreous of the eye. In order to better understand, and potentially control, these responses after injury to the CNS, it is necessary to develop a more thorough understanding of the molecules that regulate them. This study provides a step forward in that process by identifying an endogenous factor that mimics several facets of this complex response in the mammalian retina.

\section{References}

Abercrombie M (1946) Estimation of nuclear population from microtome sections. Anat Rec 94:239-247.

Anderson DH, Stern WH, Fisher SK, Erickson PA, Borgula GA (1981) The onset of pigment epithelial proliferation after retinal detachment. Invest Ophthalmol Vis Sci 21:10-16.

Anderson DH, Stern WH, Fisher SK, Erickson PA, Borgula (1983) Retinal detachment in the cat: the pigment epithelial-photoreceptor interface. Invest Ophthalmol Vis Sci 24:906-926.

Backhovens H, Gheuens J, Slegers $H$ (1987) Expression of glial fibrillary acidic protein in rat $\mathrm{C} 6$ glioma relates to vimentin and is independent of cell-cell contact. J Neurochem 49:348-354. 
Baird A, Bohlen P (1990) Fibroblast growth factors. In: Peptide growth factors and their receptors (Sporn MB, Roberts AB, eds), pp 369418. Berlin: Springer.

Baird A, Esch F, Gospodarowicz D, Guillemin R (1985) Retina- and eye-derived endothelial growth factors: partial molecular characterization and identity with acidic and basic fibroblast growth factors. Biochemistry 24:7855-7860.

Bignami A (1986) Astrocytes. In: Diseases of the nervous system, Vol 1 (Ashbury A, McKhann G, McDonald W, cds), pp 124-138. London: Heinemann Medical.

Bignami A, Dahl D (1979) The radial glia of Müller in the rat retina and their response to injury. An immunofluorescence study with antibodies to the glial fibrillary acidic (GFA) protein. Exp Eye Res 28: 63-69.

Bjorkland H, Bignami A, Dahl D (1985) Immunohistochemical demonstration of glial fibrillary acidic protein in normal rat Müller glia and retinal astrocytes. Neurosci Lett 54:363-368.

Boycott BB, Hopkins JM (1981) Microglia in the retina of monkey and other mammals: its distinction from other types of glia and horizontal cells. Neuroscience 6:679-688.

Bradshaw RA, Cavanaugh KP (1990) Isolation and characterization of growth factors. In: Peptide growth factors and their receptors (Sporn MB, Roberts AB, eds), pp 17-36. Berlin: Springer.

Calvo JL, Carbonell AL, Boya J (1991) Co-expression of glial fibrillary acidic protein and vimentin in reactive astrocytes following brain injury in rats. Brain Res 566:333-336.

Cavanaugh JB (1970) The proliferation of astrocytes around a needle wound in the rat brain. J Anat 106:471-487.

Cirillo A, Arruti C, Courtois Y, Jeanny JC (1990) localization of basic fibroblast growth factor binding sites in the chick embryonic neural retina. Differentiation 45:161-167.

de Juan E, Steffansson E, Ohira A (1990) Basic fibroblast growth factor stimulates ${ }^{3} \mathrm{H}$-thymidine uptake in retinal venular and capillary endothelial cells in vivo. Invest Ophthalmol Vis Sci 31:1238-1244.

Du Bois M, Bowman PD, Goldstein GW (1985) Cell proliferation after ischemic infarction in gerbil brain. Brain Res 347:245-252.

Erickson PA, Fisher SK, Anderson DH, Stern WH, Borgula GA (1983) Retinal detachment in the cat: the outer nuclear and outer plexiform layers. Invest Ophthalmol Vis Sci 24:927-942.

Erickson PA, Fisher SK, Guerin CJ, Anderson DH, Kaska DD (1987) Glial fibrillary acidic protein in Müller cells after retinal detachment. Exp Eye Res 44:37-48.

Fayein NA, Courtois Y, Jeanny JC (1990) Ontogeny of basic fibroblast growth factor binding sites in mouse ocular tissues. Exp Cell Res 188: $75-88$.

Finklestein SP, Apostilides PJ, Caday CG, Prosser J, Philips MF, Klagsburn M (1988) Increased basic fibroblast growth factor (bFGF) immunoreactivity at the site of focal brain wounds. Brain Res 460:253259.

Fisher SK, Anderson DH (1989) Cellular effects of detachment on the neural retina and the retinal pigment epithelium. In: Retina, Vol 3 (Glaser BM, Michels RG, eds), pp 165-190. St. Louis: Mosby.

Fisher SK, Erickson PA, Lewis GP, Anderson DH (1991) Intraretinal proliferation induced by retinal detachment. Invest Ophthalmol Vis Sci 32:1739-1748.

Giulian D, Ingeman JE (1988) Colony-stimulating factors as promoters of ameboid microglia. J Neurosci 8:4707-4717.

Giulian D, Lachman LB (1985) Interleukin-1 stimulation of astroglial proliferation after brain injury. Science 228:497-499.

Giulian D, Chen J, Ingeman JE, George JK, Naponen M (1989) The role of mononuclear phagocytes in wound healing after traumatic injury in adult mammalian brain. J Neurosci 9:4416-4429.

Glaser BM, D'Amore PA, Michels RS, Patz A, Fenselau A (1980) Demonstration of vasoproliferative activity from mammalian retina. J Cell Biol 84:298-304.

Gomez-Pinilla F, Lee JW, Cotman CW (1992) Basic FGF in adult rat brain: cellular distribution and response to entorhinal lesion and fimbria-fornix transection. J Neurosci 12:345-355.

Gospodarowicz D, Neufeld G, Schweigerer L (1986) Molecular and biological characterization of fibroblast growth factor, and angiogenic factor which also controls the proliferation and differentiation of mesoderm and neuroectoderm derived cells. Cell Differ 19:1-17.

Guérin CJ, Anderson DH, Fisher SK (1990a) Changes in intermediate filament immunolabeling occur in response to retinal detachment and reattachment in primates. Invest Ophthalmol Vis Sci 31:1474-1482.

Guérin CJ, Wolfshagen RW, Eifrig DE, Anderson DH (1990b) Im- munocytochemical identification of Müller's glia as a component of human epiretinal membranes. Invest Ophthalmol Vis Sci 31:14831491.

Hageman GS, Kirchoff-Rempe MA, Lewis GP, Fisher SK, Anderson DH (1991) Sequestration of basic fibroblast growth factor in the primate retinal interphotoreceptor matrix. Proc Natl Acad Sci USA 88:6706-6710.

Hanneken A, Lutty GA, McCleod DS, Robey F, Harvey AK, Hjelmeland LM (1989) Localization of basic fibroblast growth factor to the developing capillaries of the bovine retina. J Cell Physiol 138:115120.

Hanneken A, De Juan E, Lutty G, Hjelmeland L (1990) Basic FGF is bound to basement membrane HSPG GAGs in normal and proliferative diabetic retinas. Invest Ophthalmol Vis Sci [Suppl] 31:193.

Hiskott PS, Grierson I, Trombetta CJ, Rahi AHS, Marshall J, McLeod D (1984a) Retinal and epiretinal glia: an immunohistochemical study. Br J Ophthalmol 68:698-707.

Hiskott PS, Grierson I, McLeod D (1984b) Retinal pigment epithelial cells in epiretinal membranes: an immunohistochemical study. $\mathrm{Br} \mathrm{J}$ Ophthalmol 68:708-715.

Hjelmeland LM, Harvey AK (1988) Gliosis of the mammalian retina: migration and proliferation of retinal glia. In: Progress in retinal research, vol 7 (Osborn N, Chader J, eds), pp 259-281. Oxford: Pergamon.

Kerns JM, Hinsman EJ (1973) Neuroglial response to sciatic neurectomy. 1. Light microscopy and autoradiography. J Comp Neurol 151: 237-254.

Kivela T, Tarkkanen A, Virtanen I (1986) Intermediate filament in the human retina and retinoblastoma. An immunohistochemical study of vimentin, glial fibrillary acidic protein and neurofilaments. Invest Ophthalmol Vis Sci 27:1075-1084.

Kroll AJ, Machemer R (1968) Experimental retinal detachment in the owl monkey. III. Electron microscopy of retina and pigment epithelium. Am J Ophthalmol 66:410-427.

Lee VHL, Prince KJ, Frambach DA, Martini B (1989) Drug delivery to the posterior segment. In: Retina, Vol 1 (Ogden TE, Schachat AP, eds), 483-498. St. Louis: Mosby.

Lewis GP, Erickson PA, Kaska DD, Fisher SK (1988) An immunocytochemical comparison of Müller cells and astrocytes in the cat retina. Exp Eye Res 47:839-853.

Lewis GP, Erickson PA, Guerin CJ, Anderson DH, Fisher SK (1989) Changes in the expression of specific Müller cell proteins during longterm retinal detachment. Exp Eye Res 49:93-111.

Logan A (1988) Elevation of acidic fibroblast growth factor mRNA in lesioned rat brain. Mol Cell Endocrinol 56:275-278.

Machemer R (1978) Pathogenesis and classification of massive periretinal proliferation. Br J Ophthalmol 62:737-747.

Mathewson $\Lambda \mathrm{J}$, Berry M (1985) Observation on the astrocyte response to a cerebral stab wound in adult rats. Brain Res 327:61-69.

Miyake T, Hattori T, Fukuda M, Kitamura T, Fujita S (1988) Quantitative studies on proliferative changes of reactive astrocytes in mouse cerebral cortex. Brain Res 451:133-138.

Morrison RS, DeVilles J, Lee YL, Bradshaw R, Eng LF (1985) Hormones and growth factors induce the synthesis of glial fibrillary acidic protein in rat brain astrocytes. J Neurosci Res 14:167-176.

Noji S, Matsuo T, Koyama E, Yamaal T, Nohno T, Matsuo N, Tanguchi S (1990) Expression pattern of acidic and basic fibroblast growth factor genes in adult rat eyes. Biochem Biophys Res Commun 168: 343-349.

Nork TM, Wallow IHL, Sramek SJ, Anderson G (1987) Müller's cell involvement in proliferative diabetic retinopathy. Arch Ophthalmol 105:1424-1429.

O'Dowd DK, Eng LF (1979) Immunocytochemical localization of the glial fibrillary acidic (GFA) protein in the Müller cells of the human retina. Soc Neurosci Abstr 5:431.

Perraud F, Labourdette G, Miehe M, Loret C, Sensenbrenner M (1988) Comparison of the morphological effects of acidic and basic fibroblast growth factors on rat astroblasts in culture. J Neurosci Kes 20:1-11.

Peyman GA, Bok D (1972) Peroxidase diffusion in the normal and laser-coagulated primate retina. Invest Ophthalmol Vis Sci 11:35-45.

Puro DG, Mano T, Chan CC, Fukuda M, Shimada H (1990) Thrombin stimulates the proliferation of human retinal glial cell. Albrecht Von Graefes Arch Klin Exp Ophthalmol 228:169-173.

Russell SR, Hageman GS (1991) Insoluble interphotoreceptor matrix is present in human vitreous following rhegmatogenous retinal detachment. Invest Ophthalmol Vis Sci [Suppl] 91:878. 
Seitelberger F (1988) Astroglial dystrophies. Neurol Neurobiol 39: 167-168.

Skoff RP, Vaughn JE (1970) An autoradiographic study of cellular proliferation in degenerating rat optic nerve. J Comp Neurol 141: 133-156.

Sporn MB, Roberts AB (1990) The multifunctional nature of peptide growth factors. In: Peptide growth factors and their receptors (Sporn MB, Roberts AB, eds), pp 3-15. Berlin: Springer.
Takamiya Y, Kohsaka S, Toya S, Otani M, Tsukada Y (1988) Immunohistochemical studies on the proliferation of reactive astrocytes and the expression of cytoskeletal proteins following brain injury in rats. Dev Brain Res 38:201-210.

Van Horn DL, Aaberg TM, Machemer R, Fenzl R (1977) Glial cell proliferation in human retinal detachment with massive periretinal proliferation. Am J Ophthalmol 84:383-393. 